\title{
Prognostic factors in thyroid carcinomas: a 17-year outcome study
}

1 Institute of Pathophysiology and Nuclear Medicine, Medical Faculty, University Ss Cyril and Methodius, Skopje, Republic of North Macedonia

${ }^{2}$ Institute of Epidemiology and Statistics with Medical Informatics, University Ss Cyril and Methodius, Skopje, Republic of North Macedonia

Correspondence to: Tanja Makazlieva Institute of Pathophysiology and Nuclear Medicine,

Medical Faculty,

University Ss Cyril and Methodius, Skopje, Republic of North Macedonia Nuclear Medicine, University Ss Cyril and Methodius, Skopje, Republic of North Macedonia Street Mother Tereza, 17

Skopje, Republic of North Macedonia tmakazlieva@medf.ukim.edu.mk

Received on Mar/17/2019 Accepted on Jul/28/2019

DOI: 10.20945/2359-3997000000175
Tanja Makazlieva ${ }^{*}$

https://orcid.org/0000-0003-0460-2116

Olivija Vaskova'

https://orcid.org/0000-0001-9958-9270

Sinisha Stojanoski ${ }^{1}$

https://orcid.org/0000-0002-4967-2102

Manevska Nevena

https://orcid.org/0000-0001-7168-3775

Daniela Miladinova'

https://orcid.org/0000-0001-7354-1308

Vesna Velikj Stefanovska ${ }^{2}$

https://orcid.org/0000-0002-0908-0751

\begin{abstract}
Objectives: The aim of our study was to evaluate the survival rate of all thyroid carcinomas (TCs) diagnosed in the 1999-2015 period in the Republic of North Macedonia and to analyze the prognostic influence of several characteristics on development of distant metastases, as well as to analyze the prognostic effect of seven clinical and constitutional features on mortality. Material and methods: A retrospective analysis of medical data from all TCs diagnosed in 1999-2015 was performed. The survival rate of all types of TCs was estimated using the Kaplan Meier method. Univariate and multivariate logistic regression analysis was applied for evaluation of the predictive role of seven clinical and constitutional characteristics for development of distant metastases, and the univariate Cox-proportional model was applied for evaluation of the predictors for mortality. Results: A total of 422 TC cases were diagnosed in the 17-year period, with an average survival time of 212.99 months. Results of the univariate regression analysis showed that dimension at initial ultrasound and histopathological type of tumor were significantly predictive variables for distant metastases. Multifocal tumors vs. unifocal tumors $<15 \mathrm{~mm}$ significantly increased the probability of distant metastase by $7.401(p=0.005,95 \% \mathrm{Cl}=1.817-30.190)$ times. Age, initial lymph node involvement, number of radioiodine therapies, and histopathology of the tumor were selected as independent significant predictors for mortality. Conclusion: Our results showed an excellent overall prognosis of thyroid tumors in the Macedonian population. The dimension of the tumor, multifocality, and histopathological type were the most relevant prognostic predictive features for development of distant metastases. Arch Endocrinol Metab. 2020;64(1):30-7
\end{abstract}

Keywords

Thyroid carcinomas; survival rate; prognostic factors

\section{INTRODUCTION}

$\mathrm{T}$ hyroid carcinomas (TCs) usually arise from follicular epithelial cells. Less frequent are medullary TCs of neuroendocrine origin, and extremely rare are thyroid tumors of mesenchymal origin (1). Further classification taking into consideration genetic profiling is necessary (2). According to histopathological findings, there are three main groups of TCs: welldifferentiated (DTCs), poorly differentiated (PDTCs), and undifferentiated or anaplastic TCs (ATCs). DTCs are most prevalent, with papillary thyroid carcinoma (PTC) being the most frequent, followed by follicular thyroid carcinoma (FTC). Great diversity exists even in the PTC group, consisting of several subtypes according to distinct histopathological features, genetic molecular findings, aggressiveness, and prognosis (1-6). The most frequent are typical and follicular variants, but the most adverse are tall cell and diffuse sclerosing variants of PTC (5-8). FTC is the second most common TC, and according to the WHO classification is characterized by relatively well-differentiated cancer cells and absence of typical nuclear features of PTC (9-13).

Since 2004, based on their features, PDTCs have been introduced into the $\mathrm{WHO}$ classification as a separate category (between DTCs and ATCs) $(14,15)$. Undifferentiated or ATC is a rare form, represented by 
$1-2 \%$ of TCs, but characterized by aggressive biology. It accounts for $14-50 \%$ of all deaths in TC patients, with an average survival rate of $3-5$ months, despite the use of available multimodality therapy (16). Clinical and constitutional findings are important for the initial risk stratification and prognosis, but dynamic risk stratification and reevaluation of the prognostic factors are also important during the follow-up period $(17,18)$.

The objective of our study was to evaluate the survival rate of all TCs diagnosed in Republic of North Macedonia during the 1999-2015 period and to analyze the prognostic influence of seven parameters on development of distant metastases during the follow-up period, as well as to analyze the prognostic effect of seven clinical and constitutional features on mortality.

\section{MATERIALS AND METHODS}

A retrospective analysis was performed of the medical data of all TCs in the 1999-2015 period, diagnosed at the Institute of Pathophysiology and Nuclear Medicine in Skopje, as well as the Nuclear Medicine department at the Clinical Hospital in Bitola. These departments were the two main centers treating TC patients in our country during the evaluated period; hence, we believe that in the absence of a regional cancer registry, the presented number of TCs is the most precise and representative for the whole country. The two centers used the same therapy protocol and total and near total thyroidectomy was mostly applied in all differentiated TCs larger than $1 \mathrm{~cm}$; iodine ablation and radioiodine therapies were performed according appropriate protocols (10). ATCs were further treated at the Oncology department, and medullary TCs were only surgically treated. Therapy with tyrosine kinase inhibitors was not available in our country for the evaluated period. We divided TC cases into five groups: (1) Carcinoma anaplasticum (ATC); (2) Carcinoma folliculare (FTC), including Hurthle cell carcinoma; (3) Carcinoma papillare (PTC); (4) Carcinoma medullare (MTC); and (5) mixed group of rare types of thyroid tumors (RTTs), such as tumors from mesenchymal origin lymphomas, sarcomas, and metastatic tumors in the thyroid. Cumulative proportional survival rate was analyzed using the Kaplan-Meier method for the entire sample of TCs and separately for the five distinct types.

Statistical analysis was performed using SPSS, v.21.0 for Windows. Data are expressed as percentages, mean, and standard deviation. Univariate and multivariate logistic regression analysis was performed for evaluation of the possible predictive role of seven clinical and constitutional characteristics for development of distant metastases. We evaluated the possible predictive role of gender, age, familial anamnesis, echogenicity of the primary tumor, dimension of the tumor at initial ultrasound (US), preoperative thyroid hormonal status, and histopathological type of the tumor.

The univariate Cox-proportional model was applied for evaluation of the independent predictors for mortality. Seven clinical and constitutional variables were included: age at initial diagnosis, gender, presence of lymph node involvement at initial presentation, number of applied radioiodine therapies for differentiated TCs, total received dose of radioiodine only for differentiated TCs, period from surgery to radioiodine ablation, and histopathology type of the tumor. The level of significance was $P<0.05$.

\section{RESULTS}

A total of 422 TC cases were diagnosed and treated in the 17-year period (1999-2015) at two main thyroid departments. From the total of 422 cases, histopathological findings and precise histopathological diagnosis of the tumor were well documented in 386 (91.47\%) cases, the most common being PTC with 307 cases $(79.5 \%)$, followed by FTC with 42 cases (10.9\%), MTC with 16 (4.1\%), ATC with 12 (3.1\%), and other RTT with $9(2.3 \%)$ cases. We found appropriate data for evaluation of distant metastases in half of the TC patients $(218 / 422 ; 51.66 \%)$, of which $70(32.11 \%)$ had metastatic disease (Table 1$)$.

Results of the univariate logistic regression analysis showed dimension of the tumor at initial US

Table 1. Analysis of TC patients according to developed metastases

\begin{tabular}{lcc}
\hline Metastatic status & Number & $\%$ \\
\hline Without & 148 & 67.88 \\
Undefined & 10 & 4.6 \\
Skeletal & 2 & 0.92 \\
Lung & 25 & 11.47 \\
Skeletal and lung & 2 & 0.92 \\
Parotid gland & 3 & 1.38 \\
Neck lymph nodes & 25 & 11.47 \\
Local recurrence & 3 & 1.38 \\
Total & 218 & 100 \\
\hline
\end{tabular}


examination and histopathological type of tumor to be significant predictive variables for distant metastases (Table 2). We found that a tumor dimension of 16$50 \mathrm{~mm}$ vs. tumor $<15 \mathrm{~mm}(p<0.05)$ significantly increased the probability of distant metastases by 6.154 $(p=0.004,95 \% \mathrm{CI}=1.762-21.489)$ times. Multifocal tumors $v$ s. tumors $<15 \mathrm{~mm}(p<0.05)$ significantly increased the probability of distant metastases by 7.401 $(p=0.005,95 \% \mathrm{CI}=1.817-30.190)$ times (Table 2).

Analysis of histopathology results showed that FTC vs. PTC $(p<0.05)$ significantly increased the probability of distant metastases by $2.568(p=0.018,95 \% \mathrm{CI}=$ 1.176-5.608) times (Table 2).

All variables selected through univariate logistic regression analysis as significant predictors for development of distant metastases were analyzed using multiple logistic regression analysis (Table 3 ). The results obtained with this method confirmed the following independent predictors for metastatic disease: dimension of the tumor $(16-50 \mathrm{~mm},>51 \mathrm{~mm}$ and multifocal) compared to tumors $<15 \mathrm{~mm}$ and histopathological type ATC vs. PTC (Table 3 ).

The mean survival time of all TC patients was 212.99 (95\% CI $=204.6-221.4)$ months (Figure 1). The mean survival time by histopathological type was as follows: for PTC, 223.07 (95\% CI = 218.6-227.5) months; for FTC, $161(95 \%$ CI $=138.8-184.7)$ months; for MTC, 179 (95\% CI = 155.5-203.3) months; for RTT, 8.7 (95\% CI $=3.3-14.0)$ months; and for ATC, $22.3(95 \% \mathrm{CI}=10.2-$ $34.4)$ months. There was a significant difference between different histopathological types $(p<0.05)$ (log-rank/ Mantel-Cox: chi-square $=62.245 ; \mathrm{df}=4 ; p<0.0001)$.

Table 2. Predictive role of seven variables and probability for distant metastases, univariate logistic regression analysis

\begin{tabular}{|c|c|c|c|c|c|c|c|c|}
\hline \multirow{2}{*}{ Variable } & \multirow{2}{*}{ B } & \multirow{2}{*}{ S.E. } & \multirow{2}{*}{ Wald } & \multirow{2}{*}{ df } & \multirow{2}{*}{ Sig. } & \multirow{2}{*}{$\operatorname{Exp}(B)$} & \multicolumn{2}{|c|}{ 95\% C.I. for EXP(B) } \\
\hline & & & & & & & Lower & Upper \\
\hline \multicolumn{9}{|c|}{ Gender - reference category/male } \\
\hline Female & $(0.655)$ & 0.349 & 3.516 & 1 & 0.061 & 0.520 & 0.262 & 1.030 \\
\hline \multicolumn{9}{|c|}{ Age - reference category $/ \leq 45$ years } \\
\hline$>45$ years & $(0.018)$ & 0.291 & 0.004 & 1 & 0.951 & 0.982 & 0.555 & 1.738 \\
\hline \multicolumn{9}{|c|}{ Dimension of the tumor on US/ $<15 \mathrm{~mm}$} \\
\hline $16-50 \mathrm{~mm}$ & 1.817 & 0.638 & 8.111 & 1 & $0.004^{*}$ & 6.154 & 1.762 & 21.489 \\
\hline$>51 \mathrm{~mm}$ & 2.708 & 0.771 & 12.337 & 1 & $0.000^{*}$ & 15.000 & 3.310 & 67.978 \\
\hline Multifocal & 2.002 & 0.717 & 7.803 & 1 & $0.005^{*}$ & 7.407 & 1.817 & 30.190 \\
\hline \multicolumn{9}{|c|}{ Echogenicity - reference category/hyperechogenic } \\
\hline Anechogenic & (19.006) & 14210.361 & 0.000 & 1 & 0.999 & 0.000 & 0.000 & . \\
\hline Hypoechogenic & 1.759 & 1.092 & 2.593 & 1 & 0.107 & 5.806 & 0.682 & 49.406 \\
\hline Isoechogenic & 2.197 & 1.269 & 2.997 & 1 & 0.083 & 9.000 & 0.748 & 108.310 \\
\hline Inhomogeneous & 1.099 & 1.089 & 1.018 & 1 & 0.313 & 3.000 & 0.355 & 25.339 \\
\hline \multicolumn{9}{|c|}{ Familial anamnesis - reference category/no } \\
\hline Positive & $(0.376)$ & 0.375 & 1.003 & 1 & 0.316 & 0.687 & 0.329 & 1.433 \\
\hline \multicolumn{9}{|c|}{ Hormonal status - reference category/euthyroid } \\
\hline Hypothyroid & (20.321) & 40192.970 & 0.000 & 1 & 1.000 & 0.000 & 0.000 & ' \\
\hline Hyperthyroid & 0.323 & 0.657 & 0.241 & 1 & 0.623 & 1.381 & 0.381 & 5.009 \\
\hline Subclinical hyper. & 0.372 & 0.757 & 0.241 & 1 & 0.623 & 1.450 & 0.329 & 6.390 \\
\hline Subclinical hypo. & $(0.322)$ & 0.687 & 0.219 & 1 & 0.640 & 0.725 & 0.188 & 2.789 \\
\hline \multicolumn{9}{|c|}{ Histopathological type - reference category/PTC } \\
\hline FTC & 0.943 & 0.399 & 5.600 & 1 & $0.018^{*}$ & 2.568 & 1.176 & 5.608 \\
\hline MTC & (20.195) & 17974.843 & 0.000 & 1 & 0.999 & 0.000 & 0.000 & \\
\hline $\mathrm{RTT}$ & 22.211 & 40192.970 & 0.000 & 1 & 1.000 & 44.644 & 0.000 & . \\
\hline ATC & 2.617 & 1.109 & 5.570 & 1 & $0.018^{*}$ & 13.696 & 1.558 & 120.361 \\
\hline
\end{tabular}

Dependent variable - distant metastases. ${ }^{*}$ Significant for $p<0.05$. 
Table 3. Multiple logistic regression analysis of predictors for distant metastases

\begin{tabular}{|c|c|c|c|c|c|c|c|c|}
\hline \multirow{2}{*}{ Variable } & \multirow{2}{*}{ B } & \multirow{2}{*}{ S.E. } & \multirow{2}{*}{ Wald } & \multirow{2}{*}{ Df } & \multirow{2}{*}{ Sig. } & \multirow{2}{*}{$\operatorname{Exp}(B)$} & \multicolumn{2}{|c|}{ 95\% C.I. for EXP(B) } \\
\hline & & & & & & & Lower & Upper \\
\hline \multicolumn{9}{|c|}{ Dimension of the tumor on US/ $<15 \mathrm{~mm}$} \\
\hline $16-50 \mathrm{~mm}$ & 1.492 & 0.650 & 5.268 & 1 & $0.022^{*}$ & 4.447 & 1.244 & 15.905 \\
\hline$>51 \mathrm{~mm}$ & 2.637 & 0.802 & 10.817 & 1 & $0.001^{*}$ & 13.966 & 2.902 & 67.210 \\
\hline Multifocal & 1.984 & 0.718 & 7.626 & 1 & $0.006^{*}$ & 7.271 & 1.779 & 29.723 \\
\hline \multicolumn{9}{|c|}{ Histopathological type - reference category/ PTC } \\
\hline FTC & 0.527 & 0.503 & 1.098 & 1 & 0.295 & 1.694 & 0.632 & 4.544 \\
\hline MTC & (20.269) & 19039.427 & 0.000 & 1 & 0.999 & 0.000 & 0.000 & . \\
\hline RTT & 22.211 & 40192.970 & 0.000 & 1 & 1.000 & 44.644 & 0.000 & . \\
\hline ATC & 2.729 & 1.127 & 5.865 & 1 & $.015^{\star}$ & 15.310 & 1.682 & 139.324 \\
\hline
\end{tabular}

Dependent variable - distant metastases. ${ }^{*}$ Significant for $p<0.05$.

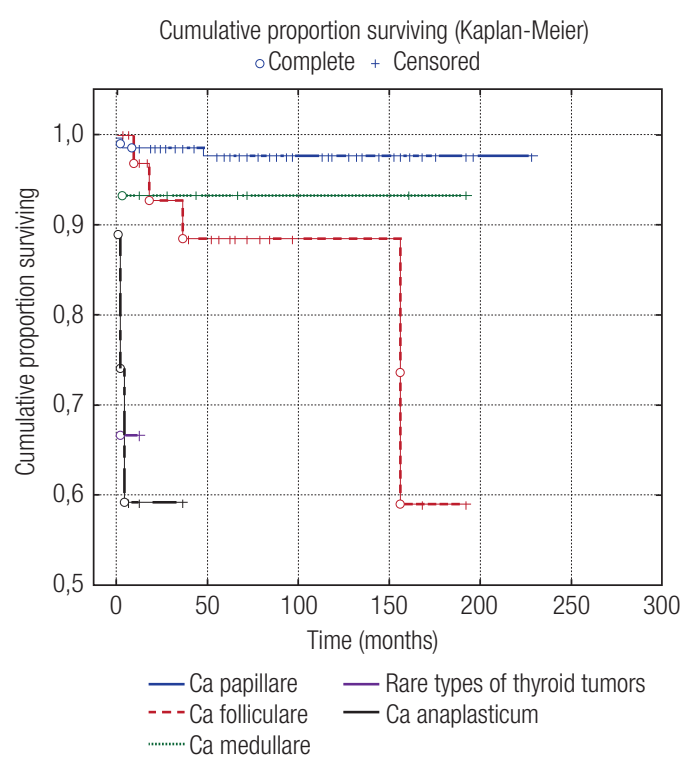

Figure 1. Overall survival in patients with TCs according to histopathological types.

The worst prognosis was observed in the mixed group consisting of other RTTs, with a survival time longer than 10 months in $67 \%$ of patients, while only $58 \%$ of ATC patients survived more than 25 months (Table 4).

Four parameters (age, lymph node involvement at initial presentation, number of radioiodine therapies, and histopathological type of the tumor) were selected through the Cox-proportional model as independent significant predictors for mortality (Table 5). Age > 45 significantly increased likelihood of death events by $42.9 \% /$ month (Cox-proportional model: $\operatorname{Exp}$ (B) $(\mathrm{HR})=8.429[p=0.005,95 \% \mathrm{CI}=1.933-36.759])$
Table 4. Analysis of survival rate according to different histopathological types of TC

\begin{tabular}{|c|c|c|c|c|}
\hline \multirow{3}{*}{$\begin{array}{l}\text { Histopathological } \\
\text { types of TC }\end{array}$} & \multicolumn{4}{|c|}{ Mean } \\
\hline & \multirow{2}{*}{$\begin{array}{c}\text { Estimation } \\
\text { (months) }\end{array}$} & \multirow{2}{*}{$\begin{array}{l}\text { Std. } \\
\text { Error }\end{array}$} & \multicolumn{2}{|c|}{ 95\% confidence interva } \\
\hline & & & $\begin{array}{l}\text { Lower } \\
\text { bound }\end{array}$ & $\begin{array}{l}\text { Upper } \\
\text { bound }\end{array}$ \\
\hline PTC & 223.068 & 2.255 & 218.648 & 227.488 \\
\hline FTC & 161.768 & 11.713 & 138.810 & 184.726 \\
\hline MTC & 179.400 & 12.173 & 155.541 & 203.259 \\
\hline $\mathrm{RTT}$ & 8.667 & 2.722 & 3.332 & 14.001 \\
\hline ATC & 22.333 & 6.183 & 10.214 & 34.453 \\
\hline For all types & 212.993 & 4.267 & 204.630 & 221.356 \\
\hline
\end{tabular}

$(p<0.05)$. Neck lymph node metastases at initial examination of the patients also significantly increased probability of death events by $46.7 \% /$ months (Coxproportional model: $\operatorname{Exp}(\mathrm{B})(\mathrm{HR})=3.467[p=0.009$, 95\% CI $=1.368-8.787])($ Table 5$)$.

\section{DISCUSSION}

Our analysis revealed 422 cases of TCs in the period of 17 years in the total population of $2,020,157$, or a $1.22 / 10^{5}$ prevalence rate of TCs, in the Republic of North Macedonia. We evaluated seven parameters to understand the possible implications in their predictive role for development of distant metastases and mortality of TCs in the Macedonian population over the analyzed period. The average survival time for all TCs for the Macedonian population was 212.99 months, with the longest average survival time for PTC. Ninety-eight percent of patients with PTC survived longer than 16 years; similar findings were presented in the study of Ito 
Table 5. Univariate Cox Proportional model in evaluation of seven parameters as predictors for mortality

\begin{tabular}{|c|c|c|c|c|c|c|c|c|}
\hline \multirow{2}{*}{ Variables } & \multirow{2}{*}{ B } & \multirow{2}{*}{ S.E. } & \multirow{2}{*}{ Wald } & \multirow{2}{*}{ Df } & \multirow{2}{*}{ Sig. } & \multirow{2}{*}{$\operatorname{Exp}(B)$} & \multicolumn{2}{|c|}{ 95\% C.I. for EXP(B) } \\
\hline & & & & & & & Lower & Upper \\
\hline \multicolumn{9}{|c|}{ Gender - reference category/ male } \\
\hline Female & $(.234)$ & 0.567 & 0.170 & 1 & 0.680 & 0.791 & 0.260 & 2.406 \\
\hline \multicolumn{9}{|c|}{ Age - reference category / $\leq 45$ years } \\
\hline$>45$ years & 2.132 & 0.751 & 8.048 & 1 & $0.005^{\star}$ & 8.429 & 1.933 & 36.759 \\
\hline \multicolumn{9}{|c|}{ Initial lymph node involvement- reference category / absent } \\
\hline Present & 1.243 & 0.474 & 6.870 & 1 & $0.009^{*}$ & 3.467 & 1.368 & 8.787 \\
\hline \multicolumn{9}{|c|}{ Number of radioiodine therapies (RAl) } \\
\hline Number of RAl & 0.257 & 0.063 & 16.563 & 1 & $0.000^{*}$ & 1.293 & 1.142 & 1.463 \\
\hline \multicolumn{9}{|c|}{ Total dose of RAl therapy } \\
\hline Total dose & $(0.001)$ & 0.003 & 0.165 & 1 & 0.685 & 0.999 & 0.993 & 1.005 \\
\hline \multicolumn{9}{|c|}{ Period from operation till radioiodine ablative therapy } \\
\hline Months & $(0.067)$ & 0.103 & 0.429 & 1 & 0.513 & 0.935 & 0.765 & 1.143 \\
\hline \multicolumn{9}{|c|}{ Histopathological type of TC - reference category / Ca papillare } \\
\hline FTC & 1.866 & 0.638 & 8.557 & 1 & $0.003^{*}$ & 6.462 & 1.851 & 22.557 \\
\hline MTC & 1.418 & 1.097 & 1.669 & 1 & 0.196 & 4.127 & 0.480 & 35.458 \\
\hline $\mathrm{RTT}$ & 3.720 & 1.128 & 10.885 & 1 & $0.0001^{*}$ & 41.267 & 4.527 & 376.172 \\
\hline ATC & 3.694 & 0.755 & 23.964 & 1 & $0.000^{*}$ & 40.224 & 9.164 & 176.559 \\
\hline
\end{tabular}

Dependent variable - alive/dead. * Significant for $p<0.05$.

Y and cols. $(19,20)$. On the other hand, only $59 \%$ of FTC patients survived longer than 13 years; the average survival time for FTC patients was 161 months. Ninetyfour percent of patients with MTC survived longer than 12 years, which is similar to the findings in the literature (10,21-24). Differences were detected in the survival of ATC group of patients, because our results showed a longer average survival of 22.3 months $(95 \% \mathrm{CI}=10.2-$ 34.4 ), compared to the average survival of 6 months reported in the literature (10). In the study of Nachalon $\mathrm{Y}$ and cols., the outcome of ATC patients varied greatly depending on the type of selected treatment, whether it was radiotherapy, chemotherapy protocol, palliative surgery alone, or combined therapy $(10,25)$.

Our results from multiple logistic regression analyses revealed a significant association of dimension and histopathological type of tumor as independent predictors for appearance of metastases. Tumors with a dimension of $15-50 \mathrm{~mm},>51 \mathrm{~mm}$, and multifocal tumors were more often associated with distant metastases during the follow-up period compared to tumors smaller than $15 \mathrm{~mm}$ at initial US examination, underlining the importance of early diagnosis. This finding suggest that the US-guided fine needle aspiration biopsy (FNAB) should be considered even in smaller lesions (less than $10 \mathrm{~mm}$ ) when there is a suspicious US, because this could lead to earlier diagnosis and better prognosis (26).

Our research revealed that multifocal PTCs are frequent and were associated with more aggressive nature of the disease and with metastatic disease, compared to tumors smaller than $15 \mathrm{~mm}$. One study analyzed the molecular characteristics of multifocal PTCs in 17 patients with RET/PTC rearrangements, and in 15 cases, different types of this genetic rearrangement were identified, suggesting that they were different tumors independently developed in the organism with genetic predisposition and appropriate external influences (27). A recent meta-analysis comprising 21 articles showed that multifocality was associated with an increased risk of lymph node involvement, extrathyroidal extension, and disease recurrence (28). Another study also found that multifocality and increasing number of tumor foci were associated with disease recurrence, with more aggressive features and poorer prognostic outcome (29). Multifocality was the most common feature in PTCs, leading to the conclusion that total thyroidectomy might be more appropriate in this type of tumor due to the possibility of small foci of disease present in the contralateral thyroid lobe, thus lowering the possibility of locoregional recurrence of the disease. 
The second independent predictor for distant metastasis was histopathological type of the thyroid tumor. In the subgroup of DTC, FTC was more frequently associated with metastatic disease 2.568 -fold in comparison with PTC. This is important because FNAB is more prone to erroneous and inappropriate diagnosis of FTC because very often, a small capsular and vascular invasion might not be detected in the FNAB sample. Lee EK and cols. analyzed the serum thyroglobulin (sTg) level as a potential biomarker in differentiation among FTC and benign thyroid follicular lesions, and according to their study, preoperative $\mathrm{Tg}$ levels had high specificity in predicting thyroid cancer in the case of suspicious follicular neoplasm, suggesting possible usefulness as a marker in the cytological diagnosis of indeterminate nodules (30).

Clinical experiences showed that the dimension of the tumor is not always correlated with biological aggressiveness and prognosis in DTC $(31,32)$. These observations and advances in molecular techniques imposed the need for new TC classification, and in addition to histopathological evaluation, introducing molecular genetic profiling should be considered in reclassifying TCs and preparing for individualized therapeutic maneuvers adjusted according to specified genetic mutation profiles $(33,34)$.

Prognostication of thyroid tumors can be made at initial presentation with several different, but similar, prognostic scoring systems. For follicular cell-derived tumors, the AGES (age, histologic grade of the tumor, extent of extrathyroidal invasion or distant metastases, and size of the primary tumor) score system, AMES (patient age, presence of distant metastases, extent and size of the primary tumor) score, MACIS (metastasis, patient age, completeness of resection, local invasion, and tumor size) score, and the TNM (tumor, node, metastasis) system were introduced (35).

Few risk stratification systems have been introduced for scoring the disease, such as AMES, MACIS, and American Joint Committee on Cancer (AJCC) TNM classifications (10). These classification systems enable initial risk stratification of the patients, but Tuttel and cols. and Momesso and cols. also suggested ongoing, dynamic risk stratification during follow-up of the patients $(18,36,37)$. Age is one constitutional factor that is considered in many stratification systems for TCs. Differentiated TC patients under a certain age cutoff are considered to be at less risk than those who are older. For example, age 55 was the cutoff point for continuous variables in the Memorial Sloan Kettering (grade, age, metastasis, extent, size, or GAMES) and AJCC/UICC systems (8th edition) (37), but there is a lack of consensus among the staging systems regarding the age threshold that has to be adopted (38).

We evaluated the prognostic influence of seven independent characteristics on the outcome of the disease, and four characteristics, according to the Cox-proportional model, were revealed as significant prognostic predictors for survival: age, lymph node involvement at initial presentation, number of radioiodine therapies, and histopathological type of thyroid tumor. In our study, age $>45$ years compared to $\leq 45$ years, as well as histopathological type FTC $v s$. PTC, significantly $(p<0.05)$ increased the probability of a death event. Another feature evaluated in our study was the need for an increased number of radioiodine therapies, which pointed out an unfavorable prognosis in PTC and FTC, probably due to dedifferentiation of the TCs. Due to enlargement of the tumor for one evaluated group, the radioiodine therapy was increased by $15.038 \mathrm{mCi}$.

Approximately $80 \%$ of patients with DTC are cured after initial therapy and have excellent prognosis (10, 18). Mazzaferri and cols. performed a similar analysis in the Italian population, and of 213 patients with DTC, $75 \%$ reached complete response to treatment after 12 months. The same group of authors analyzed the prognostic relevance of a few factors on survival rate in 1510 patients, without initial distant metastases. They concluded that the probability of a death event increased with age above 40 years, size of the tumor $>\mathrm{lcm}$, local tumor invasion and initial neck lymph node involvement, FTC histopathology, and delay in treatment. Their findings are similar to the results obtained in our study. These data point out the importance of careful initial risk stratification and appropriate initial treatment, as well as wise selection of the methods used in treatment in terms of avoiding overtreatment or incomplete therapy at the start (27).

The prognostic significance of initial neck lymph node involvement in DTC is still controversial. Several studies found an increased risk for local recurrence in patients with initial lymph node involvement, and our study revealed a significant correlation between the initial metastatic disease in neck lymph nodes and total radioiodine therapy received by patients and more frequent recurrence in this group of patients $(31,32,39)$. Due to these findings, there is still an ongoing debate 
about the extent of surgical treatment with respect to neck lymphadenectomy. According to contemporary guidelines, there are two possibilities: bilateral central neck lymphadenectomy and/or modified lateral neck compartment dissection, only if enlarged lymph nodes have been detected preoperatively or intraoperatively $(7,18,28)$. According to our findings, a careful preoperative neck examination is necessary for initial risk assignment and for selection of an appropriate surgical approach.

The limitations in our study were the heterogeneity of the thyroid tumors included in the analyses, considering the different types of TCs together, as well as possible influence of different therapy protocols applied. However, the limitations of this research point toward topics to be addressed in the future.

In conclusion, our results showed an excellent overall prognosis of thyroid tumors in the Macedonian population. From seven clinical and constitutional features, dimension and histopathological type of thyroid tumors were the most relevant prognostic predictive features for development of distant metastases in the evaluated group of patients. Our findings suggest that diagnosis of small primary tumors is important in improving survival rate, and detection of multifocality and neck lymph node involvement should be considered as increasing risk stratification factors. These characteristics, according to our analyses, could be important because they could have a significant impact on selecting the appropriate type of surgical treatment. Further studies including analysis of different therapy approaches on the outcome of TCs, as well as studies evaluating prognostic factors separately for different histopathological types of TCs, are needed for completing the evaluation of our group of patients.

Disclosure: no potential conflict of interest relevant to this article was reported.

\section{REFERENCES}

1. McDougall R. Management of thyroid cancer and related nodular disease. Springer-Verlag London 2006.

2. Katoh H, Yamashita K, Enomoto T, Masahiko W. Classification and general considerations of thyroid cancer. Ann Clin Pathol. 2015;3(1):1045-54.

3. World Health Organization (WHO) classification 2017. Pathology Outlines.com available from: website. Available from: http:// www.pathologyoutlines.com/topic/thyroidwho.html.

4. Scopa CD. Histopathology of thyroid tumors. An Overview. Hormones. 2004;3(2):100-10.
5. Romei C, Elisei R. RET/PTC translocations and clinico-pathological features in human papillary thyroid carcinoma. Front Endocrinol (Lausanne). 2012;3:54.

6. Lloyd RV, Buehler D, Khanafshar E. Papillary thyroid carcinoma variants. Head Neck Pathol. 2011;5(1):51-6.

7. Li Volsi VA. Papillary thyroid carcinoma: an update. Mod Pathol. 2011;24:S1-S9.

8. Girardi FM, Barra MB, Zettler CG. Variants of papillary thyroid carcinoma: association with histopathological prognostic factors. Braz J Otorhinolaryngol. 2013;79(6):738-44.

9. Schlumberg MJ. Papillary thyroid carcinoma, Orphanet encyclopedia, March 2004. Available from: https://www.orpha. net/data/patho/GB/uk-PTC.pdf.

10. Schumberger M, Pacini F, Tutle RM. Thyroid tumors, 4th edition, Paris: Institute Medico-Educatif, 2015.

11. Sobrinho-Simões M, Eloy $C$, Magalhães J, Lobo C, Amaro T. Follicular thyroid carcinoma. Mod Pathol. 2011;24:S10-S18.

12. Collini P, Sampietro G, Rosai J, Pilotti S. Minimally invasive (encapsulated) follicular carcinoma of the thyroid gland is the low-risk counterpart of widely invasive follicular carcinoma but not of insular carcinoma. Virchows Arch. 2003;442(1):71-6.

13. D'Avanzo A, Treseler P, Ituarte PHG, Wong M, Streja L, Greenspan FS, et al. Follicular thyroid carcinoma: Histology and prognosis. Cancer. 2004;100(6):1123-9.

14. Volante M, Collini P, Nikiforov YE, Sakamoto A, Kakudo K, Katoh R, et al. Poorly differentiated thyroid carcinoma: The Turin proposal for the use of uniform diagnostic criteria and an algorithmic diagnostic approach. Am J Surg Pathol. 2007;31(8):1256-64.

15. Volante M, Papiotti M. Poorly differentiated thyroid carcinoma: 5 years after the 2004 WHO classification of endocrine tumours. Endocr Pathol. 2010;21(1):1-6.

16. Nagaiah G, Hossain A, Mooney CJ, Parmentier J, Remick SC. Anaplastic thyroid cancer: A review of epidemiology, pathogenesis, and treatment. J Oncol. 2011;2011:542358.

17. Tuttle RM, Tala $H$, Shah J, Leboeuf $R$, Ghossein $R$, Gonen M, et al. Estimating risk of recurrence in differentiated thyroid cancer after total thyroidectomy and radioactive iodine remnant ablation: using response to therapy variables to modify the initial risk estimates predicted by the new American Thyroid Association staging system. Thyroid. 2010;20(12):1341-9.

18. Haugen BR, Alexander EK, Bible KC, Doherty GM, Mandel SJ, Nikiforov YE, et al. 2015 American Thyroid Association management guidelines for adult patients with thyroid nodules and differentiated thyroid cancer, the American thyroid association guidelines task force on thyroid nodules and differentiated thyroid cancer. Thyroid. 2016;26(1):1-133.

19. Ito $Y$, Miyauchi A, Kihara M, Fukushima M, Higashiyama T, Miya A, et al. Overall survival of papillary thyroid carcinoma patients: A single-institution long-term follow-up of 5897 patients. World J Surg. 2018;42(3):615-22.

20. Sebastian SO, Gonzales JMR, Paricio PP, Perez JS, Flores DP, Madrona AP, et al. Papillary thyroid carcinoma: Prognostic index for survival including histological variety. Arch Surg. 2000;135(3):272-77.

21. Verburg FA, Mader U, Tanase K, Thies ED, DiessI S, Buck AK, et al. Life expectancy is reduced in differentiated thyroid cancer patients $>45$ years old with extensive local tumor invasion, lateral lymph node, or distant metastases at diagnosis and normal in all other DTC patients. J Clin Endocrinol Metab. 2013;98(1):172-80.

22. De Groot JW, Plukker JT, Wolffenbuttel BH, Wiggers T, Sluiter WJ, Links TP. Determinants of life expectancy in medullary thyroid cancer: age does not matter. Clin Endocrinol (Oxf). 2006;65(6):729-36. 
23. Steliarova-Fouchere E, O'Callaghan M, Ferlay J, Masuyer E, Rosso S, Forman D, et al. The European cancer observatory: A new data resource. Eur J Cancer. 2015;51(9):1131-43.

24. Pellegriti G, Frasca F, Regalbuto C, Squatrito S, Vigneri R. Worldwide increasing incidence of thyroid cancer: Update on epidemiology and risk factors. J Cancer Epidemiol. 2013;2013:965212.

25. Nachalon Y, Stern-Shavit S, Bachar G, Shvero J, Limon D, Popovtzer A. Aggressive palliation and survival in anaplastic thyroid carcinoma. JAMA Otolaryngol Head Neck Surg. 2015;141(12):1128-32.

26. Gweon HM, Son EJ, Youk JH, Kim JA. Thyroid nodules with Bethesda system III cytology: Can ultrasonography guide the next step? Ann Surg Oncol. 2013;20(9):3083-88.

27. Mazzaferri EL, Kloos RT. Clinical review 128: Current approaches to primary therapy for papillary and follicular thyroid cancer. $\mathrm{J}$ Clin Endocrinol Metab. 2001;86(4):1447-63.

28. Joseph KR, Edirimanne S, Eslick GD. Multifocality as a prognostic factor in thyroid cancer: A meta-analysis. Int J Surg. 2018:50;121-5.

29. Qu N, Zhang L, Ji Q, Zhu Y, Wang Z, Shen Q, et al. Number of tumor foci predicts prognosis in papillary thyroid cancer. BMC Cancer. 2014;14:914.

30. Lee EK, Chung KW, Min HS, Kim TS, Kim TH, Ryu JS, et al. Preoperative serum thyroglobulin as a useful predictive marker to differentiate follicular thyroid cancer from benign nodules in indeterminate nodules. J Korean Med Sci. 2012;27(9):1014-18.

31. Rouxel A, Hejblum G, Bernier MO, Lle PY, Gaux FM, Mansour G, et al. Prognostic factors associated with the survival of patients developing loco-regional recurrences of differentiated thyroid carcinomas. J Clin Endocrinol Metab. 2004;89(11):5362-68.

32. Lin JD, Liou MJ, Chao TC, Weng HF, Ho YS. Prognostic variables of papillary and follicular thyroid carcinoma patients with lymph node metastases and without distant metastases. Endocr Relat Cancer. 1999;6(1):109-15.

33. Xing M. Molecular pathogenesis and mechanisms of thyroid cancer. Nat Rev Cancer. 2013;13(3):184-99.

34. Faam B, Ghaffari MA, Ghadiri A, Fereidoun A. Epigenetic modifications in human thyroid cancer. Biomed Rep. 2015;3(1):3-8.

35. Dean DS, Hay ID. Prognostic indicators in differentiated thyroid carcinoma. Cancer Control. 2000;7(3):229-39.

36. Momesso DP, Vaisman F, Yang SP, Bulzico DA, Corbo R, Vaisman $M$, et al. Dynamic risk stratification in patients with differentiated thyroid cancer treated without radioactive iodine. J Clin Endocrinol Metab. 2016;101(7):2692-700.

37. Tuttle RM, Haugen B, Perrier ND. Updated American Joint Committee on Cancer/Tumor-Node-Metastasis Staging System for Differentiated and Anaplastic Thyroid Cancer (Eighth Edition): What Changed and Why? Thyroid. 2017;27(6):751-56.

38. Shi RL, Qu N, Liao T, Wei WJ, Wang YL, Ji QH. The trend of age group effect on prognosis in differentiated thyroid cancer. Sci Rep. 2016;8;6:27086.

39. Mazzaferri EL, Robbins J, Spencer CA, Braverman LE, Pacini F, Wartofsky $L$, et al. A consensus report of the role of serum thyroglobulin as a monitoring method for low-risk patients with papillary thyroid carcinoma. J Clin Endocrinol Metab. 2003;88(4):1433-41. 